\title{
Enthesitis related arthritis as the early stage of juvenile spondyloarthritis
}

\author{
L Rutkowska-Sak*, E Musiej-Nowakowska, M Wierzbowska, I Slowinska and \\ B Lisowska
}

Address: Institute of Rheumatology, Warsaw, Poland

* Corresponding author

from $15^{\text {th }}$ Paediatric Rheumatology European Society (PreS) Congress

London, UK. 14-17 September 2008

Published: 15 September 2008

Pediatric Rheumatology 2008, 6(Suppl I):P8I doi:I0.I I86/I546-0096-6-SI-P8 I

This abstract is available from: http://www.ped-rheum.com/content/6/SI/P8I

(c) 2008 Rutkowska-Sak et al; licensee BioMed Central Ltd.

\section{Background}

Peripheral enthesitis related arthritis (ERA) are the major clinical features in the juvenile onset spondyloarthritis (JSpA).

\section{Objectives}

To analyze the clinical characteristic of a population of patients with JSpA who presented ERA as their only clinical symptoms as the onset of the disease.

\section{Methods}

We have studied a group of 80 children diagnosed with JSpA following the ILAR criteria, selecting only those who expressed ERA as initial symptoms of the disease.

\section{Results}

$41 \%$ patients with a mean age of 13 years (range 6-18 years) proved to have ERA.

The mean disease duration was 4,1 years (range 0,2-9 years).

They had enthesitis most frequent in Achilles tendon and plantar fascia - 33\% patients; dactylitis - 30\% patients and enthesitis of the site of attachment of the patellar tendon to the tibial tubercle $-6 \%$.

$76,8 \%$ patients presented arthritis involving peripheral joints and additionally $6,6 \%$ of them presented axial skeleton distribution.

\section{Conclusion}

ERA are most frequently and characteristic initial clinical features of spondyloarthritis. 